\title{
Effect of secretin on portal venous flow
}

\author{
L Bolondi, S Gaiani, S Li Bassi, G Zironi, P Casanova, L Barbara
}

\begin{abstract}
In this study we evaluated the effect of two different doses of secretin on portal haemodynamics (by pulsed Doppler associated with real time ultrasound) in $\mathbf{2 4}$ healthy humans. In 12 subjects (group $A$ ) we administered an intravenous dose of 75 clinical units of secretin and in the remaining 12 (group B) a dose of $20 \mathrm{CU}$. In all subjects the following parameters were studied before, during, and for 10 minutes after secretin administration: (a) calibre of the portal vein, (b) mean velocity of portal venous flow, and (c) volume of portal venous flow. In three subjects in each group we also evaluated the changes in flow in the superior mesenteric artery. Secretin injection induced a slight increase in both groups in comparison to basal values of portal vein calibre (mean of maximal per cent increase $+25 \%$ in group $A$, not significant, and $+16.7 \%$ in group $B$, not significant) and a noticeable increase of mean velocity (mean of maximal per cent increases $+61.4 \%$ in group $A, p<0.005$, and $+65.4 \%$ in group $B$, $\mathbf{p}<0.01$ ) and flow volume (mean of maximal per cent increase $+127 \%$ group $A, p<0.005$, and $+114 \%$ group $B, p<0.005)$. The magnitude of the haemodynamic changes did not differ significantly between the two groups. Doppler investigation of the superior mesenteric artery showed a marked increase of flow velocity (mean of maximal per cent increase $+218 \%$ in group $A$ and $+246 \%$ in group B) and flow volume (mean of maximal per cent increase $+276 \%$ in group $\mathbf{A}$ and $+311 \%$ in group B). These data suggest that secretin has an appreciable vasoactive effect and induces a significant increase in portal venous flow even at doses much lower than those necessary for a maximal stimulation of exocrine pancreatic secretion.
\end{abstract}

Splanchnic hyperaemia due to mesenteric arterial dilatation and increased portal venous flow has been found to occur in normal subjects after a meal. ${ }^{1-3}$ Coupled with observations that many humoral substances are released into the circulation after meals, many hormones, or autacoids, have been proposed as mediators of functional changes in splanchnic haemodynamics.

The principal agents that have been assigned a role in the complex regulation of liver blood . flow $^{45}$ are reported to be: intrinsic hepatic vasoregulation and extrinsic innervation; adrenergic and cholinergic substances; autacoids (bradykinin, serotonin, histamine, prostaglandins) and vasoconstrictor peptides (angiotensin, vasopressin). Data have also been collected regarding the possible role of changes in the composition and osmolarity of portal blood.

Among the gut hormones, glucagon has been shown to induce splanchnic vasodilatation and increased portal venous pressure in dogs, ${ }^{6-8}$ in normal humans, and in patients affected by cirrhosis of the liver. ${ }^{9}$ Many other substances have shown a vasoactive effect on liver blood flow: synthetic pentagastrin reduces hepatic arterial and portal venous resistance in the dog, ${ }^{10}$ and intravenous cholecystokinin increases portal venous blood flow and portal venous pressure without having any effect on hepatic arterial or intrahepatic portal venous vascular resistance. ${ }^{10}$ Experimental studies have also shown that intraarterial infusion of secretin induces dilatation of mesenteric vasculature and increases portal flow ${ }^{11-13}$ and pancreatic blood flow at pharmacological doses. ${ }^{14}$

In this study we evaluated by means of a duplex Doppler technique the effect on portal venous flow of different doses of intravenous secretin in healthy humans to outline the presence, if any, and the magnitude of the haemodynamic response to the hormone.

\section{Methods}

SUBJECTS

A total of 24 normal subjects were entered into this study. Informed consent was obtained in each case. The study was performed in all subjects in a supine position and in the early morning, after overnight fasting, to avoid changes due to posture ${ }^{1516}$ and the influence of meals on portal haemodynamics. ${ }^{23}$ All cases were randomly allocated to two different groups. In 12 subjects (group A: five men and seven women; age range $17-70$ years, mean 38.2 years) we administered over one minute an intravenous dose $(75 \mathrm{CU})$ of secretin (Secretolyn, Hoechst) which was proved to induce a maximal stimulation of exocrine pancreatic secretion. ${ }^{17}$ In the other 12 subjects (group B: six men and six women; age range $20-57$ years, mean 40.5 years) a lower dose $(20 \mathrm{CU})$ was administered intravenously over one minute. For control purposes, in four subjects in each group the investigation was repeated after the intravenous administration ( $1 \mathrm{~min}$ ) of corresponding volumes of saline on a different day.

\section{INSTRUMENTATION AND HAEMODYNAMIC}

\section{PARAMETERS}

Real time ultrasound equipment with $3.5 \mathrm{MHz}$ linear, convex, and mechanical sector transducers (Esaote-Hitachi AUC 940 and 450), provided by pulsed Doppler devices operating at a frequency of 3.5 and $2.5 \mathrm{MHz}$, was used. In all subjects the following parameters were studied immediately before, during, and continuously for 10 minutes after secretin administration: (a) calibre of the portal vein; this was achieved by calculating the anteroposterior diameter (in $\mathrm{mm}$ ) 
during suspended respiration at the largest point where the Doppler signal was obtained; (b) mean velocity $\left(\mathrm{V}_{\text {mean }}\right)$ of the portal venous flow $(\mathrm{cm} / \mathrm{s})$; (c) volume $(\mathrm{F})$ of the portal venous flow $(\mathrm{ml} /$ min).

The same parameters were also evaluated in the superior mesenteric artery in a subgroup of six subjects (three in group A and three in group B) to investigate the eventual effect of secretin on the arterial splanchnic bed. Measurements were taken $3-5 \mathrm{~cm}$ from the origin. ${ }^{2}$

For the duplex Doppler study the vessel was first identified at real time ultrasonography by placing the transducer on the plane of the longitudinal axis of the vessel, and then the sample volume was positioned at the centre of the vessel. The duplex system allows simultaneous measurement of flow velocity and vessel diameter at the exact point where the sample volume is positioned, avoiding errors due to the discrepancy between the point of Doppler shift registration and vessel measurement. ${ }^{18}$ Our equipment displays the angle between the sonic beam and the longitudinal axis of the vessel lumen, and we chose an angle of less than 60 degrees, avoiding larger beam-vessel angles, because of the cosine dependence of velocity measurement error with angle. ${ }^{19}$ Flow velocity (V) is directly calculated by the equipment from the Doppler spectral analysis, using the formula:

$$
\mathrm{V}=\mathrm{Fd} . \mathrm{C} / 2 \text { Fo. COS } \alpha \text {, }
$$

as described by Gill, ${ }^{20}$ where Fd is the Doppler frequency shift, $C$ the velocity of sound in the tissues $(1500 \mathrm{~m} / \mathrm{s})$, Fo the emitted ultrasonic wave frequency, and $\alpha$ the angle of incidence between the sonic beam and the longitudinal axis of the vessel. In the present study we measured the 'mean velocity of flow' $\left(\mathrm{V}_{\text {mean }}\right)$ in the portal vein and in the superior mesenteric artery. Because flow in a channel structure is laminar that is, formed by concentric layers of different velocities, increasing from the vessel wall towards the axis - the most reliable method for calculating the actual $\mathrm{V}_{\text {mean }}$ by Doppler is the 'even insonation' method. This is achieved by using a sample volume as large as the vessel diameter, taking into account the peripheral component. Our equipment can calculate $\mathrm{V}_{\text {mean }}$ directly from the Doppler spectral analysis. The high-pass filter was kept at its lowest setting (100 $\mathrm{Hz}$ ). We made $\mathrm{V}_{\text {mean }}$ calculation on Doppler traces of 4-6 $\mathrm{s}$ in order to average eventual changes of flow velocity in the portal vein related to cardiac and respiratory cycles, which are also reduced by examining the patients during suspended respiration. In the superior mesenteric artery we considered a trace of three cardiac cycles. Volume $(F)$ of flow in both portal vein and superior mesenteric artery was obtained by this formula: $F=V_{\text {mean }} \cdot \pi r^{2}$, where $r$ represents the half diameter of the vessel.

A videotape recording of the whole study was made in each case to allow careful and complete measurements in patients undergoing evaluation of both portal vein and superior mesenteric artery and to reconsider possible sources of errors in taking measurements. Arterial blood pressure and heart rate (evaluated on electrocardiographic trace) were measured basally and during the whole period of study in each subject.

\section{STATISTICAL ANALYSIS}

Calibres, $\mathrm{V}_{\text {mean }}$, and flow of the portal vein and the superior mesenteric artery are presented as mean (SD). One way analysis of variance (Anova, Statview Apple Computer Inc) was used to compare values of these parameters at each time interval with basal ones in groups A and B after secretin injection, and in the group injected with saline. Increases in calibre, $\mathrm{V}_{\text {mean }}$, and flow volumes in the two groups are also expressed as maximal per cent variations over basal values, and were compared between group $A$ and group $B$ by the non-parametric Mann-Whitney U test.

\section{Results}

Arterial blood pressure and heart rate did not significantly change during the period of study in any of the subjects. No appreciable modification of the calibre and of the haemodynamic profile of the portal vein was observed during and after saline administration. Changes induced by secretin administration are reported separately for each haemodynamic parameter. Results concerning the portal vein are summarised in Tables I and II.

\section{CALIBRE}

Figure 1 shows the mean (SD) values of the calibre of the portal vein before and after the two doses of secretin. Basal values were $9(2 \cdot 4) \mathrm{mm}$ in group $A$ and $9.6(1.2) \mathrm{mm}$ in group $B$. In most

TABLE I Maximal increase (expressed as per cent variation) of diameter $(0)$, flow velocity $\left(V_{\text {mean }}\right)$, and flow volume $(F)$ in the portal vein after intravenous injection of $75 C U$ of secretin (group A)

\begin{tabular}{llllcc}
\hline $\begin{array}{l}\text { Case } \\
\text { No }\end{array}$ & $\begin{array}{l}\text { Age } \\
\text { (years) }\end{array}$ & Sex & 0 & $V_{\text {mean }}$ & $F$ \\
\hline 1 & 17 & $\mathrm{~F}$ & 45 & 27 & 161 \\
2 & 19 & $\mathrm{~F}$ & 12 & 33 & 70 \\
3 & 31 & $\mathrm{M}$ & 38 & 53 & 181 \\
4 & 24 & $\mathrm{~F}$ & 25 & 100 & 153 \\
5 & 40 & $\mathrm{~F}$ & 22 & 42 & 53 \\
6 & 22 & $\mathrm{M}$ & 43 & 65 & 131 \\
7 & 70 & $\mathrm{~F}$ & 22 & 47 & 200 \\
8 & 68 & $\mathrm{~F}$ & 33 & 68 & 151 \\
9 & 70 & $\mathrm{M}$ & 10 & 92 & 133 \\
10 & 43 & $\mathrm{~F}$ & 16 & 90 & 120 \\
11 & 29 & $\mathrm{M}$ & 19 & 45 & 100 \\
12 & 36 & $\mathrm{M}$ & 25 & 75 & 78 \\
Mean & 38.2 & & 25 & $61 \cdot 4$ & $127 \cdot 6$ \\
\hline
\end{tabular}

TABLE II Maximal increase (expressed as per cent variation) of calibre $(0)$, flow velocity $\left(V_{\text {men }}\right)$, and flow volume $(F)$ in the portal vein after intravenous injection of $20 C U$ of secretin (group B)

\begin{tabular}{lllllr}
\hline $\begin{array}{l}\text { Case } \\
\text { No }\end{array}$ & $\begin{array}{l}\text { Age } \\
\text { (years) }\end{array}$ & Sex & \multicolumn{1}{c}{0} & $V_{\text {mean }}$ & \multicolumn{1}{c}{$F$} \\
\hline 1 & 42 & $M$ & 9 & 88 & 93 \\
2 & 48 & $M$ & 22 & 88 & 180 \\
3 & 57 & F & 11 & 88 & 93 \\
4 & 61 & F & 9 & 47 & 61 \\
5 & 43 & F & 11 & 88 & 131 \\
6 & 50 & F & 30 & 68 & 184 \\
7 & 28 & F & 22 & 64 & 98 \\
8 & 20 & M & 12 & 94 & 124 \\
9 & 30 & M & 20 & 35 & 94 \\
10 & 32 & F & 18 & 42 & 102 \\
11 & 46 & $M$ & 15 & 61 & 120 \\
12 & 29 & M & 21 & 50 & 90 \\
Mean & $40 \cdot 5$ & & $16 \cdot 7$ & $65 \cdot 4$ & 114 \\
\hline
\end{tabular}


Figure 1: Mean $(S D)$ calibre variations of the portal vein values for the differences between the calibre at each time interval $\mathrm{v}$ basal values are shown. $0=$ calibre of the portal vein. in groups $A$ and $B$ after secretin administration. $P$

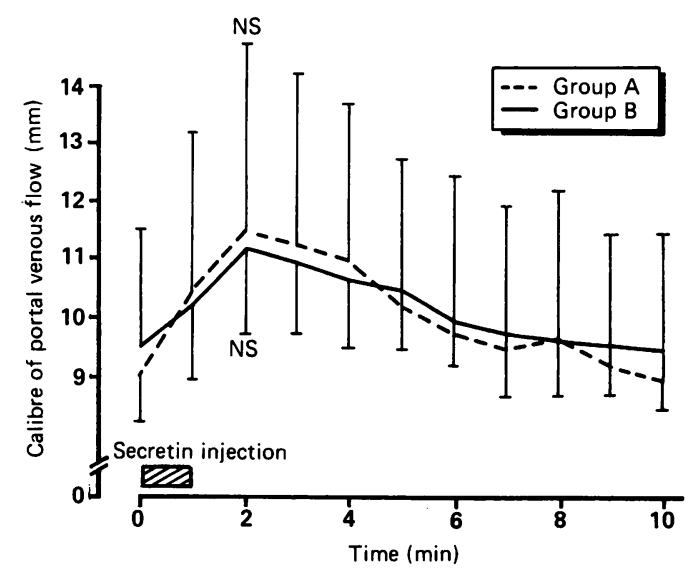

cases the maximum calibre increase was observed after $2 \mathrm{~min}$ (mean (SD) $11.5(3.2) \mathrm{mm}$, not significant, in group $A ; 11.2(1.5) \mathrm{mm}$, not significant, in group B). The mean per cent calibre increase was $25 \%$ in group A and $16.7 \%$ in group B (Tables I and II). After $4 \mathrm{~min}$ a progressive calibre decrease occurred and after 7 min (group B) and 8 min (group A) the calibre was again within basal values. In the subjects in which the superior mesenteric artery was studied basal values were $4.6(0.6) \mathrm{mm}$ in group $A$ and $4.9(0.3) \mathrm{mm}$ in group B. The mean calibre varied after secretin administration with a maximal increase at the second $\min (5 \cdot 1(0 \cdot 8) \mathrm{mm}$ in group $A$, not significant; $5.4(0.5) \mathrm{mm}$ in group $\mathrm{B}$, not significant). The mean per cent increase $(8.5 \%$ in group $A$ and $8.1 \%$ in group $B$ ) was not consistently different in the two groups.

\section{VELOCITY OF FLOW}

Basal values of $\mathrm{V}_{\text {mean }}$ in the portal vein were $19 \cdot 1$ $(5 \cdot 7) \mathrm{cm} / \mathrm{s}$ in group A and $16 \cdot 3(3 \cdot 1) \mathrm{cm} / \mathrm{s}$ in group B. Figure 2 shows changes of $V_{\text {mean }}$ in groups $A$ and $B$, expressed as mean (SD). The maximal increase in $V_{\text {mean }}$ was reached $2 \mathrm{~min}$ after the start of secretin administration (Fig 3) $(31.3(5 \cdot 2) \mathrm{cm} / \mathrm{s}, \mathrm{p}<0.005$, in group $\mathrm{A} ; 26.7$ $(6.3) \mathrm{cm} / \mathrm{s}, \mathrm{p}<0.01$, in group B). At the end of the study $V_{\text {mean }}$ returned to within basal values in 11 out of 12 subjects in both groups. The maximal increases of flow velocities, calculated as mean per cent variation over basal values, shown in Tables I and II, ranged from $27 \%$ to $100 \%$ in group $\mathrm{A}^{\circ}($ mean $=61.4)$ and from $35 \%$ to

Figure 2: Changes of $V_{\text {mean }}$ in the portal vein in groups $A$ and $B$ (expressed as mean $(S D))$ after secretin administration. $P$ values for the differences between the $V_{\text {mean }}$ at each time interval $\mathrm{v}$ basal values are shown.

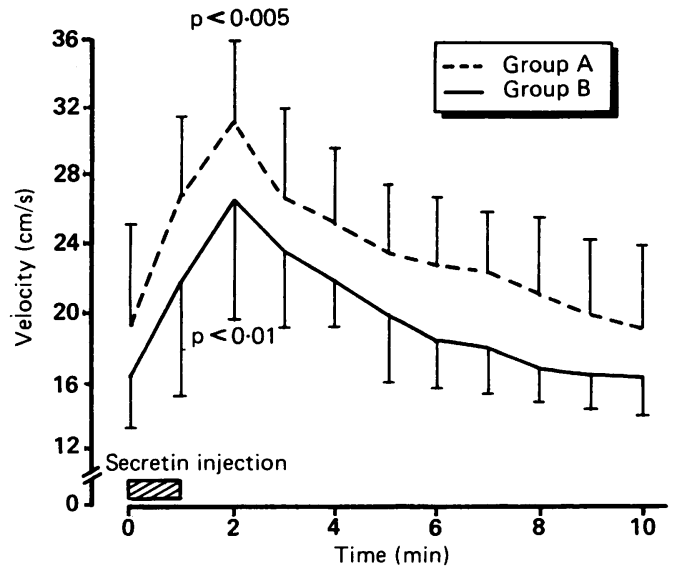

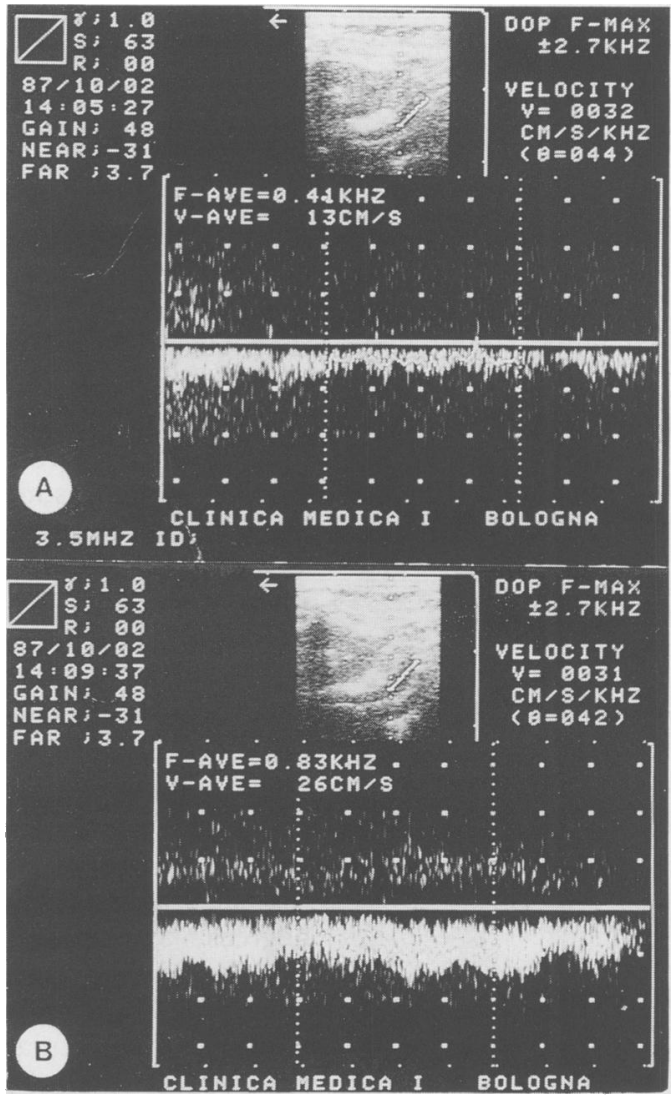

Figure 3: Duplex Doppler demonstration of maximal increase in $V_{\text {mean }}$ in the portal vein after secretin administration in case 4 of group $A$. (A) $V_{\text {mean }}(13 \mathrm{~cm} / \mathrm{s})$ in basal conditions $(2 \mathrm{~min}$ before injection $)$. (B) $V_{\text {mean }}(26 \mathrm{~cm} / \mathrm{s}) 2 \mathrm{~min}$ after injection. Date and time of examination are shown on the top left. $V_{\text {mea }}$ has been calculated in both cases on Doppler traces of $4 \mathrm{~s}$.

$94 \%$ in group B $($ mean $=65.4)$. The mean per cent increase did not significantly differ between the two groups.

In the subjects in which superior mesenteric artery was studied, basal values of $\mathrm{V}_{\text {mean }}$ were $22 \cdot 7(4 \cdot 2) \mathrm{cm} / \mathrm{s}$ in group A and $21 \cdot 7(3 \cdot 1) \mathrm{cm} / \mathrm{s}$ in group B. At 2 min $V_{\text {mean }}$ was raised at 76.7 (4) in group $A(p<0.05)$ and $67.7(3.6)$ in group $B$ $(\mathrm{p}<0.05)$. The mean per cent increase $(246 \%$ in group A and $218 \%$ in group B) was not consistently different in the two groups.

\section{FLOW VOLUME}

Basal values of flow in the portal vein were 782 (353) $\mathrm{ml} / \mathrm{min}$ in group A and $727(212) \mathrm{ml} / \mathrm{min}$ in group B. Figure 4 shows the noticeable increase of flow after both $75 \mathrm{CU}$ and $20 \mathrm{CU}$ of secretin. Maximal values $(1957(921) \mathrm{ml} / \mathrm{min}, \mathrm{p}<0.005$, in group $\mathrm{A}$, and $1579(575) \mathrm{ml} / \mathrm{min}, \mathrm{p}<0.005$, in group B) corresponded to the maximal increase of calibre and $\mathrm{V}_{\text {mean }}$, and were reached between one and two minutes (Fig 5). The increase of flow varied among the subjects examined: Tables I and II show these changes reported as per cent variation in comparison with basal values. In most cases it was well over $90 \%$ in both group A $(127 \cdot 6 \%)$ and group B (114\%) with no significant difference between the two groups.

In the subjects in which superior mesenteric artery was studied basal values of flow were 227 (29) $\mathrm{ml} / \mathrm{min}$ in group A and $252(49) \mathrm{ml} / \mathrm{min}$ in group B. Maximal mean values were 937 (271) 
Figure 4: Duplex Doppler demonstration of maximal increase in $V_{\text {mean }}$ in the superior mesenteric artery in case 10 of group $A$. ( $A)$ $V_{\text {mean }}(18 \mathrm{~cm} / \mathrm{s})$ in basal conditions (just before injection). (B) $V_{\text {mean }}$ $(76 \mathrm{~cm} / \mathrm{s}) 2 \mathrm{~min}$ after injection. Date and time of the examination are shown on the top left. $V_{\text {mean }}$ has been calculated in both cases on Doppler traces of $4 \mathrm{~s}$. after secretin administration

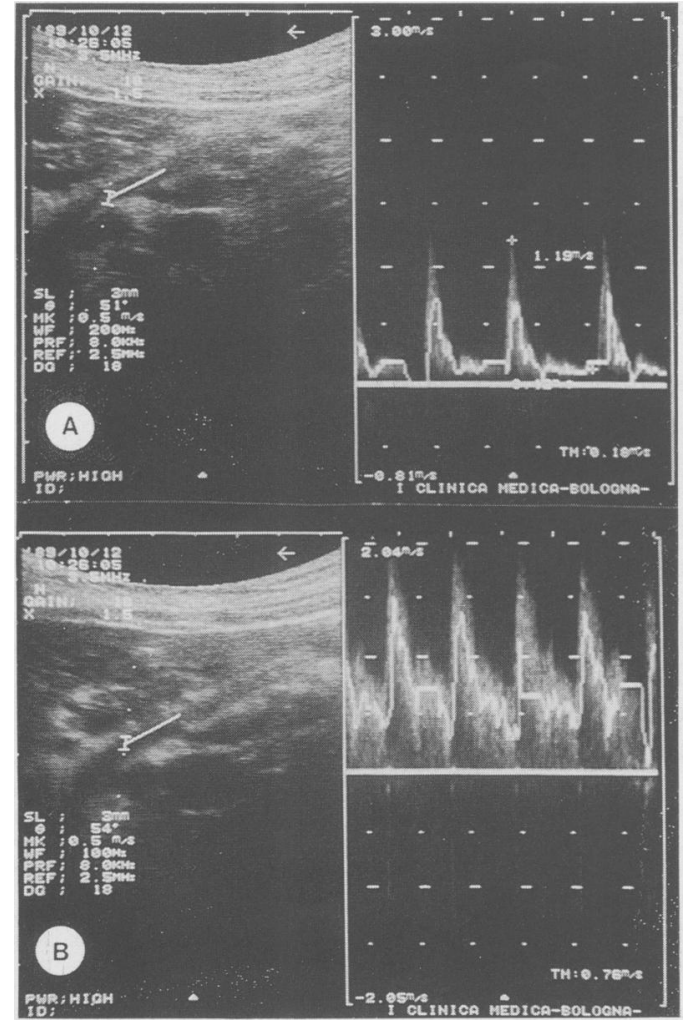

$\mathrm{ml} / \mathrm{min}$ in group A $(\mathrm{p}<0.05)$ and $926(206) \mathrm{ml}$ min in group $B(p<0.05)$. The mean per cent increase ( $311 \%$ in group A and $276 \%$ in group B) was not consistently different in the two groups.

\section{Discussion}

Most studies on nervous and hormonal regulation of blood flow in the liver have been made using isolated hepatic perfusion systems in anaesthetised animals. Apart from the possible effects of total anaesthesia on liver blood flow and differences between animals and humans, it is often difficult to compare results obtained from different laboratories due to differences in experimental techniques. ${ }^{4}$

Duplex Doppler ultrasound is actually the only method which allows a non-invasive and dynamic visualisation of the portal vein together with the evaluation of haemodynamic parameters. The quantitative assessment of blood velocity and flow by Doppler method in the portal vein ${ }^{20-22}$ and in the superior mesenteric artery has been reported in previous studies. ${ }^{23-25}$ Possible sources of errors with this method were outlined in a cautionary review by Gill ${ }^{19}$ and reconsidered by Burns and coworkers ${ }^{2627}$ and

Figure 5: Changes of flow volume in the portal vein in groups $A$ and $B$ (expressed as mean $(S D))$ after secretin administration. $P$ values for the differences between the flow volume at each time interval $\mathrm{v}$ basal values are shown.

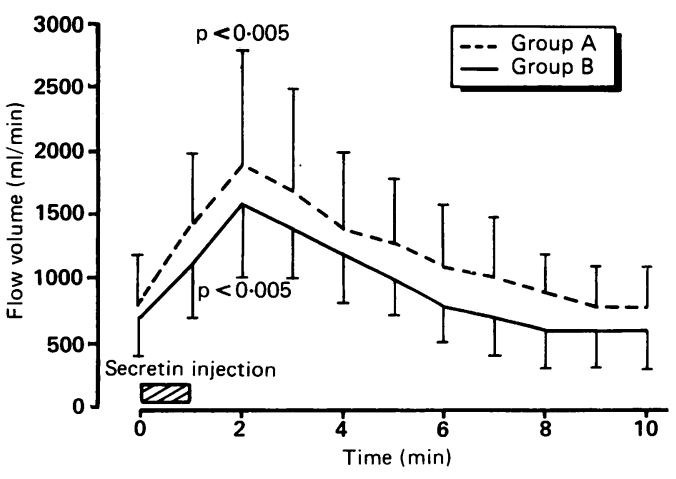

Dauzat and Pomier Layrargues. ${ }^{28}$ They include the measurement of cross sectional area of the vessel and the angle of approach. Errors in measuring cross sectional area may affect calculation of flow volumes but not $V_{\text {mean }}$. It is, however, accepted that repeated measurements of the diameters reduce the error of flow calculation to within $10 \% .^{25}$ Furthermore, it has been shown recently ${ }^{28}$ that variations in the cross diameter of the portal vein are not significantly related to flow measurement errors. The angle of approach, if larger than $60^{\circ}$, may appreciably affect the calculation of flow velocity owing to the dependence of the cosine of the angle of velocity measurement. This study was performed only on subjects where it was possible to use angles below $60^{\circ}$ (usually from $30^{\circ}$ to $50^{\circ}$ ).

In these cases an uncertainty of $5^{\circ}$ (which is difficult to reach in our opinion) results in an error of flow velocity ranging from 5 to $10 \%$. The filter of $100 \mathrm{~Hz}$ used may also eliminate low velocity signals (usually under $4 \mathrm{~cm} / \mathrm{s}$ when the angle of approach is below $60^{\circ}$ ). This means that the possible overestimation of $\mathrm{V}_{\text {mean }}$ in basal conditions may result in a lower difference with values measured after secretin administration. Therefore the validity of our results is not affected.

Measurements of changes of flow velocity and volume in the same subject under different conditions are even more acceptable, since any potential experimental errors should be a constant in a subject both before and after drug administration. Duplex Doppler seems therefore to be a suitable method for in vivo monitoring of acute haemodynamic changes induced by hormones, drugs, and other substances on portal blood flow. ${ }^{1828}$

Using this technique we have shown that an intravenous bolus of secretin induces an impressive increase of portal flow velocity and volume in humans. These findings are in agreement with previous experimental reports showing dilatation of mesenteric vasculature and increased portal venous blood flow after intra-arterial injection of this hormone. ${ }^{11}$

Similar results have also been reported in humans by Okazaki et al ${ }^{1}$ using a maximal dose (1 U/kg) of secretin. We found that the response of portal flow to secretin stimulation is early (within $2 \mathrm{~min}$ ) and in some cases an appreciable effect was noted just before the end of the bolus injection. This behaviour is closely similar to the response of the main pancreatic duct to secretin stimulation $^{29}$ and may suggest a direct effect of the hormone on splanchnic vasculature. The pronounced increase of superior mesenteric arterial flow observed in the six cases examined indicates a direct effect of secretin on arterial splanchnic bed and suggests that secretin modulates portal flow indirectly by changing mesenteric arterial inflow rather than directly affecting portal vascular tone. We cannot, however, exclude the role of reduced portal and intrahepatic resistance, as was reported to occur in experimental studies on isolated portal vein. ${ }^{30}$ The disappearance of the effect of secretin six to eight minutes after the beginning of the injection is related to its short plasma half life, which is about two to four minutes. ${ }^{31} 32$ 
Glucagon, a polypeptide with structural similarity to secretin ${ }^{33}$ (each sharing a 14 amino acid sequence), has been shown to induce splanchnic vasodilatation and increase portal venous pressure. On the basis of experimental studies this effect seems to be a result of an increase in both inflow volume $e^{34}$ and intrahepatic portal resistance. ${ }^{7}$ It is unlikely that this hormone has a physiological role in postprandial hyperaemia since the release of glucagon depends mainly on a substantial drop in plasma glucose concentrations, and a glucose containing meal causes a decrease rather than an increase of serum glucagon. ${ }^{36}$ It has been suggested that cholecystokinin, which increases portal venous blood flow and portal venous pressure in dogs, ${ }^{10}$ is the most likely candidate for increasing intestinal blood flow in the postprandial state. ${ }^{37}$ Secretin may add to the known effect of cholecystokinin on postprandial blood flow in a similar way to their combined effect on pancreatic exocrine function.

As far as this problem is concerned the final question is to establish if the observed effect of secretin on portal flow is only pharmacological or even physiological. The significant increase of portal vein and superior mesenteric arterial flow observed after the lower dose of secretin $(20 \mathrm{CU})$, which corresponds to less than one third of the dose used to stimulate the maximal exocrine pancreatic secretion, shows a high sensitivity of the splanchnic vascular bed to secretin stimulation. This might suggest a role for secretin in the modulation of postprandial splanchnic hyperaemia. This point cannot, however, be established from our data and further investigation is needed to confirm this hypothesis.

1 Okazaki K, Miyazaki M, Ohnishi S, Ito K. Effects of food intake and various extrinsic hormones on portal blood flow in patients with liver cirrhosis demonstrated by pulsed Doppler with the Octoson. Scand $\mathcal{F}$ Gastroenterol 1986; 21: 1029-38.

2 Moneta GL, Taylor DC, Helton S, Mulholland MW, Strandness E Jr. Duplex ultrasound measurement of postprandial intestinal blood flow: effect

3 Gaiani S, Bolondi L, Li Bassi S, Santi V, Zironi G, Barbara L. Effect of meal on portal hemodynamics in healthy humans and in patients with chronic liver disease: Hepatology 1989; 9: 815-9.

4 Richardson PDI, Withrington PG. Liver blood flow. I. Intrinsic and nervous control of liver blood flow. Gastroenterology 1981; 81: 159-73.

5 Richardson PDI, Withrington PG. Liver blood flow. II. Effects of drugs and hormones on liver blood flow. Gastroenterology 1981; 81: 356-75.

6 Kock NG, Roding B, Hahnloser P, et al. The effect of glucagon on hepatic blood flow. Arch Surg 1970; 100: 147-9.

7 Darle N, Lim RC, Lindberg B. The effect of glucagon on total liver blood flow after occlusion of the hepatic artery. Acta Chir Scand 1976; 142: 43-6.

8 Richardson PDI, Withrington PG. The effects of intraportal infusions of glucagon on the hepatic arterial and portal venous vascular beds of the dog: inhibition of hepatic arterial vasoconstrictor responses to noradrenaline. Pfluegers Arch (Eurf Physiol) 1978; 378: 135-40.

9 Silva G, Chesta J, Bosch J, et al. Effects of glucagon on hepatic and systemic hemodynamics in patients with cirrhosis and portal hypertension. $₹$ Hepatol $1987 ; 5$ (suppl 1): S92.

10 Post JA, Hanson KM. Hepatic, vascular and biliary responses to infusion of gastrointestinal hormones and bile salts. Digestion 1975; 12: 65-77.

11 Ross G. Cardiovascular effects of secretin. Am F Physiol 1970 218: 1166-70.

12 Richardson PDI, Withrington PG. The vasodilator actions of isoprenaline, histamine, prostglandin $\mathrm{E}_{2}$, glucagon and secretin on the hepatic vascular bed in the dog. $B$ f Pharmacol 1976; 57: 581-8.

13 Richardson PDI, Withrington PG. The effect of glucagon, secretin, pancreozymin and pentagastrin on the hepatic arterial vascular bed of the dog. Br f Pharmacol 1977; 59: 147-56.

14 Chung RS, Safaie-Shirazi S. The effect of secretin on pancreatic blood flow in the awake and anesthetized dog. Proc Soc Exp Biol Med 1983; 173: 620 .

15 Rahim N, Adam JE. Ultrasound demonstration of variations in normal portal vein diameter with posture. $\mathrm{Br} \mathcal{F}$ Radiol 1985; 58: $313-4$

16 Ohnishi K, Saito M, Nakayama T, et al. Portal venous hemodynamics in chronic liver disease: effects of posture change and exercise. Radiology 1985; 155: 757-61.

17 Konturek SJ. Pancreatic dose-response curves to intravenous secretin in man. Gastroenterology 1970; 58: 828-32

18 Brown HS, Halliwell M, Qamar M, Read A, Evans JM, Wells PNT. Measurement of normal portal venous flow by Doppler ultrasound. Gut 1989; 30: 503-9.

19 Gill RW. Measurement of blood flow by ultrasound: accuracy and sources of error. Ultrasound Med Biol 1985; 4: 625-41.

20 Gill RW. Pulsed Doppler with B-mode imaging for quantita tive blood flow measurement. Ultrasound Med Biol 1979; 5: 223-35.

21 Ohnishi K, Saito M, Koen H, Nakayama T, Nomura F, Okuda K. Pulsed Doppler flow as a criterion of portal venous velocity: comparison with cineangiographic measurements. Radiology 1985; 154: 495-8.

22 Moryiasu F, Ban N, Nishida O, et al. Clinical application of an ultrasonic duplex system in the quantitative measurement of portal blood flow. $\mathcal{F}$ Clin Ultrasound 1986; 14: 579-88.

23 Jaeger K, Bollinger A, Valli C, Ammann R. Measurement of mesenteric blood flow by duplex scanning. $\mathcal{F}$ Vasc Surg 1986; 3: 462-9.

24 Sato S, Ohnishi K, Sugita S, Okuda K. Splenic artery and superior mesenteric artery blood flow: nonsurgical Doppler US measurements in healthy subjects and patients with chronic liver disease. Radiology 1987; 164: 347-52

25 Eik-Nes SH, Marsal K, Kristoffersen K. Methodology and basic problems related to blood flow studies in the human fetus. Ultrasound Med Biol 1984; 10: 329-37.

26 Burns PN, Taylor KJW, Blei AT. Doppler flowmetry in portal hypertension. Gastroenterology 1987; 92: 824-6.

27 Burns PN. Interpretation and analysis of Doppler signals. In: Taylor KJW, Burns PN, Wells PNT, eds. Clinical applications of Doppler Ultrasound. New York: Raven, 1988.

28 Dauzat M, Pomier Layrargues G. Portal vein blood flow measurements using pulsed Doppler and electromagnetic flowmetry in dogs: a comparative study. Gastroenterology flowmetry in dog

29 Bolondi L, Gaiani S, Gullo L, Labò G. Secretin administration induces a dilatation of main pancreatic duct. Dig Dis $\mathrm{Sci}$ 1984; $29: 802-8$.

30 Fara JW. Effects of gastrointestinal hormones on vascular smooth muscle. Am $\mathscr{f}$ Dig Dis 1975; 20: 346-53.

31 Curtis PJ, Fender HR, Rayford PL, et al. Disappearance halftime of endogenous and exogenous secretin in dogs. Gut 1976; 17: 595-602.

32 Hacki WH. Secretin. Clin Gastroenterol 1980; 9: 609-32.

33 Jorpes JE. The isolation and chemistry of secretin and cholecystokinin. Gastroenterology 1968;55: 157-62.

34 Tibblin S, Kock NG, Schenk WG. Splanchnic hemodynamic responses to glucagon. Arch Surg 1970; 100: 84-9.

35 Ross G. Regional circulatory effect of pancreatic glucagon. Br f Pharmacol 1970; 38: 735-42.

36 Unger RH, Ohneda A, Valverde I, et al. Characterization of the responses of circulating glucagon-like immunoreactivity to intraduodenal and intravenous administration of glucose. f Clin Invest 1968; 47: 48-54

37 Granger DN, Richardson PDI, Kvietys PR, et al. Intestinal blood flow. Gastroenterology 1980; 78: 837-63. 